\title{
The Effects of Blood-flow Restriction Training on Muscle Hypertrophy, Strength, and Power in College-Age Adults
}

\author{
Meghan Rohde \\ Franklin Pierce College, rohdem@franklinpierce.edu \\ Lauren Bacsalmasi \\ Kids Place Central Pediatric Physical Therapy, grayl16@live.franklinpierce.edu \\ Quinton Erhard \\ Sawtooth CalPhysical Therapy, erhardq16@live.franklinpierce.edu \\ Tanner Lung \\ Engineered Sports, lungt16@live.franklinpierce.edu \\ Whitney Weinert \\ Engineered Sports, weinertw16@live.franklinpierce.edu
}

Follow this and additional works at: https://nsuworks.nova.edu/ijahsp

Part of the Physical Therapy Commons, and the Sports Sciences Commons

\section{Recommended Citation}

Rohde M, Bacsalmasi L, Erhard Q, Lung T, Weinert W. The Effects of Blood-flow Restriction Training on Muscle Hypertrophy, Strength, and Power in College-Age Adults. The Internet Journal of Allied Health Sciences and Practice. 2021 Jan 01;19(2), Article 12.

This Manuscript is brought to you for free and open access by the College of Health Care Sciences at NSUWorks. It has been accepted for inclusion in Internet Journal of Allied Health Sciences and Practice by an authorized editor of NSUWorks. For more information, please contact nsuworks@nova.edu. 


\title{
The Effects of Blood-flow Restriction Training on Muscle Hypertrophy, Strength, and Power in College-Age Adults
}

\begin{abstract}
Purpose: Low load BFR (LLBFR) training can produce similar strength gains as high load resistance (HLR) training, especially in cases where persons may not have the ability to toelrate heavy loads. The purpose of this study was to compare changes in strength, power, and hypertrophy between HLR (70\% $1 \mathrm{RM})$ and LLBFR (30\% 1RM). Methods: Sixteen healthy individuals, ages 23-21 (8 male, 8 female) were randomized into HLR and LLBFR groups. Obtained baseline measurements included 1-repetition maximum (1RM), thigh circumference, and vertical jump height. Each group performed back squat, Bulgarian split squat, barbell step ups, and lunges. The HL group trend $3 x$ weekly at $3 \times 8$ repetitions with 2-3 minutes rest and the LLBFR trained 2x weekly for repetitions of 30-15-15-15 with 30 seconds rest between sets and 2-3 minutes rest between exercises. Results: Significant differences were found within groups for pre-post vertical jump height, left thigh circumference, and 1RM squat. No significant difference was found between LLBFR and HLR groups in measures of vertical jump height or 1RM squat. Conclusion: LLBFR using compound, closed kinetic chain exercises may be effective for strength training in persons who may not be able to tolerate higher loads.
\end{abstract}

\footnotetext{
Author Bio(s)

Meghan J. Rohde, PT, DPT, PhD, SCS, CSCS is Assistant Professor of Physical Therapy at Franklin Pierce University in Goodyear, AZ. She is also a licensed physical therapist in the state of Arizona and Board Certified Sports Physical Therapist

Lauren Bacsalmasi, PT, DPT is a pediatric and orthopedic physical therapist at Kids Place Central Pediatric Physical Therapy in Phoenix, AZ.

Quinton Erhard, PT, DPT is an orthopedic physical therapist at Sawtooth CalPhysical Therapy in Caldwell, ID.
}

Tanner Lung, PT, DPT and Whitney Weiner, PT, DPT, are both orthopedic physical therapists at Engineered Sports in Everett, WA. 


\title{
1IJAHSP \\ The Internet Joumnal of Allied Health Sciences and Practice \\ Dedicated to allied health professional practice and education
}

Vol. 19 No. 2 ISSN 1540-580X

\section{The Effects of Blood-Flow Restriction Training on Muscle Hypertrophy, Strength, and Power in College-Age Adults}

\author{
Meghan Rohde ${ }^{1}$ \\ Lauren Bacsalmasi ${ }^{2}$ \\ Quinton Erhard 3 \\ Tanner Lung ${ }^{4}$ \\ Whitney Weinert ${ }^{4}$
}

1. Franklin Pierce University

2. Kids Place Central Pediatric Physical Therapy

3. Sawtooth CalPhysical Therapy

4. Engineered Sports

United States

\begin{abstract}
Purpose: Low load blood flow restriction (LLBFR) training can produce similar strength gains as high load resistance (HLR) training, especially in cases where persons may not have the ability to tolerate heavy loads. The purpose of this study was to compare changes in strength, power, and hypertrophy between HLR (70\% 1RM) and LLBFR (30\% 1RM). Methods: Sixteen healthy individuals, ages 23-21 (8 male, 8 female) were randomized into HLR and LLBFR groups. Obtained baseline measurements included 1-repetition maximum (1RM), thigh circumference, and vertical jump height. Each group performed back squat, Bulgarian split squat, barbell step ups, and lunges. The HL group trend $3 \times$ weekly at $3 \times 8$ repetitions with 2-3 minutes rest and the LLBFR trained $2 x$ weekly for repetitions of 30-15-15-15 with 30 seconds rest between sets and 2-3 minutes rest between exercises. Results: Significant differences were found within groups for pre-post vertical jump height, left thigh circumference, and 1RM squat. No significant difference was found between LLBFR and HLR groups in measures of vertical jump height or 1RM squat. Conclusion: LLBFR using compound, closed kinetic chain exercises may be effective for strength training in persons who may not be able to tolerate higher loads.
\end{abstract}

Keywords: resistance training, repetition maximum, blood-flow restriction 


\section{INTRODUCTION}

Blood-flow restriction is a method of hypertrophic training that is becoming increasingly popular in the bodybuilding world, as well as in therapeutic settings. This training method was first developed by Dr. Yoshiaki Sato in 1997, and it was termed "Kaatsu." 1 Since its introduction, several studies have shown the benefits of blood-flow restriction (BFR) on muscle hypertrophy and delayed muscular atrophy. Additionally, research has shown that low load BFR (LL-BFR) training can produce similar strength gains as high load resistance (HLR) training. ${ }^{2}$ This method of training could prove to be a useful tool in cases where patients may not have the ability to tolerate heavy loads, such as in the post-operative phase or with certain disorders of the bone or skeletal muscle.

The American College of Sports Medicine (ACSM) recommends exercising muscle groups 2-3 times per week for 2-4 sets of 8-12 repetitions at $60-70 \%$ of the $1 \mathrm{RM}$ to improve strength and power. ${ }^{3}$ They also recommend $2-3$ minutes of rest between sets and 48 hours of rest between bouts of exercise. ${ }^{3}$ Exercise under $50 \%$ of $1 \mathrm{RM}$ is known to improve muscular endurance. ${ }^{3}$ Many studies have shown LL-BFR training to increase strength and hypertrophy at much lower loads of $1 \mathrm{RM}$. A meta-analysis of LL-BFR training showed that strength gains can be achieved at 20-30\% $1 \mathrm{RM}$ and that 2-3 training bouts per week are most effective. ${ }^{4}$ Although there isn't a "gold standard" for the sets and reps of LL-BFR training, 30-15-15-15 with 30 seconds rest between sets appears to be most used in the current literature.5,6,7,8,9 Muscle strength and hypertrophy are typically not increased with aerobic exercise or low load resistance training; however, studies have shown that this can be obtained with BFR ${ }^{6}$.

The mechanisms of these changes are not fully understood, and numerous theories have been discussed in the literature. Growth hormone $(\mathrm{GH})$, whole blood lactate, plasma lactate, and muscle cell lactate increase with LL-BFR, stimulating muscle protein synthesis. ${ }^{9} \mathrm{GH}$ is stimulated by the acidic environment produced by increased lactate levels. ${ }^{9}$ Muscle protein synthesis signaling is increased following phosphorylation of the S6K1 signaling protein. 4,9,10 This signaling protein is elevated with LL-BFR resistance training and HLR training without BFR. ${ }^{6,9}$ Furthermore, S6K1 signaling protein is found in higher concentrations in fast twitch muscle fibers. ${ }^{6}$ The increase in S6K1 in fast twitch muscle fibers may explain the phenomenon of increased muscle mass during LL-BFR training through the increased recruitment of fast twitch muscle fibers. ${ }^{10}$ Slow twitch muscle fibers are typically recruited first; however, the hypoxic environment in LL-BFR may result in early recruitment of fast twitch fibers. ${ }^{14,10,13} \mathrm{HLR}$ training results in intramuscular environmental changes through muscular stress, while LL-BFR resulted in intramuscular environmental changes without increased load. These changes include oxygen reduction and metabolite accumulation, which have been shown to increase muscle fiber recruitment. ${ }^{10}$

In rehabilitation, gaining strength, hypertrophy/decreasing atrophy, and power are something that are essential in regaining full function. In a study by Takarada et al, participants wore BFR bands five times a day for five minutes without performing any exercise, and this was found to decrease the atrophy of the knee extensors. ${ }^{11}$ Clarkson et al showed that walking with BFR bands improved strength in older adults. ${ }^{12} \mathrm{~A}$ meta-analysis by Leonneke et al found that low load resistance training exercises had a similar effect as a hypertrophy training program. ${ }^{4}$ However, that analysis looked at a number of studies that performed isolated movements for their training, such as knee extension, knee flexion, elbow flexion, etc.

These previous studies have examined the effects of BFR in subjects who may not tolerate progressive overloads up to $70 \% 1 \mathrm{RM}$ to achieve muscle hypertrophy. While previous studies have shown an improvement in muscle hypertrophy and strength, these studies utilized exercises in isolation and walking. In early stages of rehabilitation, exercises in isolation or at lower intensity may be necessary for recovery. However, in late-stage rehabilitation, higher loads and more complex movement patterns may be necessary. The purpose of this study is to determine the effects of a functional training program on strength, hypertrophy, and power using LL-BFR.

\section{METHODS}

Subjects were a convenience sample of 17 graduate students ( 8 male, 9 female). Subjects ages ranged from 23-31 years. Participants excluded from the study were those that exhibited any contraindications to exercise on the Physical Activity Readiness Questionnaire (PAR-Q), those who were already involved in a supervised resistance training program, and those who had not been recreationally active within the past six months. One female subject was eliminated from the study after the initial testing session due to sacroiliac pain.

Subjects were then randomized into two groups of 8. Group A participated in an 8-week hypertrophy training program including the following exercises: squats, split squats, step-ups, and lunges. 1 RM for each exercise was determined initially for all participants using National Strength and Conditioning Association (NSCA) guidelines ${ }^{13}$. Before the start of the exercise programs, vital signs were measured and recorded for all participants (blood pressure, respiratory rate, and pulse rate). Vital signs were also taken at the beginning of every week for the duration of both programs, using the Welch Allyn Connex 6000 @ Vital Signs Monitor. This monitor was verified to be calibrated by a biomedical technician. Participants in Group A performed each exercise at 70\% of 
1 RM for $3 \times 8$ repetitions, with 2-3 minutes rest between sets, and 2-3 minutes rest between exercises. Sessions were completed three times per week. A minimum of 48 hours rest between sessions was required between training sessions. Group B participated in an 8-week low-intensity training program with blood flow-restriction bands with the same four exercises as listed previously. Blood flow restriction was achieved using BFR Bands $®$ (www.bfrshop.com).

BFR bands were applied to the upper thighs, at a subjective discomfort level of approximately $7 / 10$. Wilson et al found that a subjective restriction of 7/10 resulted in greater indices of muscular stress, swelling, and activation compared to work-matched controls without increasing muscular damage ${ }^{8}$. Restrictive bands were worn for the duration of each exercise set and removed while the subject was resting. Subjects in Group B performed each exercise at 30\% of their 1 RM for 30-15-15-15 repetitions, with 30 seconds rest between sets and 2 minutes rest between exercises, for two sessions per week. A minimum of 48 hours between sessions was required. Before each workout, subjects were asked to rate their overall feeling of wellness on a scale of 1-4 (1=poor, $2=$ fair, $3=$ good, $4=e x c e l l e n t)$. At the end of each workout session, all subjects were asked to rate their perceived exertion on a scale of 0-10. On rest days between workout sessions, subjects were asked to rate their muscle soreness on a scale of 0-10. Session time was recorded for each participant at each session and used to calculate session rate of perceived exertion (sRPE).

During the program, the "Two for Two Rule" was implemented for all subjects. This rule is defined by the NSCA as "If during the last two sessions of the week, the last two reps of the last two sets of an exercise are easy, then weight can be increased 5-10\%."13 At the end of each 8-week program, all participants were measured in 1 RM squat, lunge, step-up, split-squat, vertical jump height, and thigh circumference. All workouts were completed under the supervision of the research investigators at Franklin Pierce University. Subjects were instructed not to engage in any strenuous cardiovascular activity for two days before and after each testing session. Subjects were not permitted to engage in any other lower extremity strengthening or conditioning (i.e., running, cycling, CrossFit, etc.) during the entire length of the study.

Statistics were analyzed using IBM SPSS version 25. Dependent t-tests were calculated to examine differences within the groups for $1 \mathrm{RM}$ squat, thigh circumference, and vertical jump. Independent t-tests were calculated to examine differences between Group $A$ and Group $B$ for the three measures listed above. Independent $t$-tests were also calculated to examine the differences between groups for age, gender, BMI, training age, and session RPE (SRPE).

\section{RESULTS}

Before training, there were no significant differences in age (group $A=25.63$; group $B=24.63 ; p$-value $=0.372$ ), training age (group $A=5.13$; group $B=7.25 ; p$-value $=.334$ ), and $B M I$ (group $A=24.14$; group $B=22.88 ; p$-value $=0.268$ ) between the two groups. There were significant differences in the SRPE between the groups in over half of the weeks, this data is shown in table 4. Vertical jump height, $1 \mathrm{RM}$ for squat, and thigh circumference for each group pre/post training were measured. The averages for each group for pre-training can be found in table 1 and post-training can be found in table 2. Both groups significantly increased in vertical jump height (group $A=20.00$ inches, $p$-value $=0.001$; group $B=20.00$ inches, $p$-value $=0.03$ ), 1 RM squat (group $A=236.88 \mathrm{lbs}, p$ value $=<0.001$; group $B=226.88 \mathrm{lbs}, p$-value $=<0.001$ ), and left thigh circumference (group $A=53.44 \mathrm{~cm}, p$-value $=0.03$; group $B=52.38 \mathrm{~cm}, p$-value $=0.04$ ). Group $A$ did have a significant difference between pre and post right thigh circumference (group $A=$ $53.94 \mathrm{~cm} ; p$-value $=0.005$ ), but group $B$ did not with a $p$-value exceeding 0.05 . There were no significant differences between the two groups in vertical jump height, 1RM squat, and right or left thigh circumference ( $p$-values in table 3 ).

Table 1. Mean Session RPE (sRPE) Values Each Week

\begin{tabular}{|l|l|l|l|l|l|l|l|l|}
\hline & $\begin{array}{l}\text { SRPE } \\
\text { AVG (wk1) }\end{array}$ & $\begin{array}{l}\text { SRPE } \\
\text { AVG (wk2) }\end{array}$ & $\begin{array}{l}\text { SRPE } \\
\text { AVG (wk3) }\end{array}$ & $\begin{array}{l}\text { SRPE } \\
\text { AVG (wk4) }\end{array}$ & $\begin{array}{l}\text { SRPE } \\
\text { AVG (wk5) }\end{array}$ & $\begin{array}{l}\text { SRPE } \\
\text { AVG (wk6) }\end{array}$ & $\begin{array}{l}\text { SRPE } \\
\text { AVG (wk7) }\end{array}$ & $\begin{array}{l}\text { SRPE } \\
\text { AVG (wk8) }\end{array}$ \\
\hline Group A & 353.58 & 250.92 & 221.50 & 241.46 & 216.17 & 231.88 & 226.83 & 204.96 \\
\hline Group B & 391.38 & 343.44 & 318.69 & 317.50 & 287.31 & 299.88 & 259.81 & 252.94 \\
\hline & P wk1 & P wk2 & P wk3 & P wk4 & P wk5 & P wk6 & P wk7 & P wk8 \\
\hline Group A/B & 0.286 & 0.002 & 0.002 & 0.016 & 0.029 & 0.052 & 0.255 & 0.022 \\
\hline
\end{tabular}


Table 2. Mean Pre-Training Measurements

\begin{tabular}{|l|l|l|l|l|}
\hline & Pre-vertical jump & Pre 1RM squat & $\begin{array}{l}\text { Pre R thigh } \\
\text { circumference }\end{array}$ & $\begin{array}{l}\text { Pre L thigh } \\
\text { circumference }\end{array}$ \\
\hline Group A & 18.06 inches & $200.63 \mathrm{lbs}$ & $52.00 \mathrm{~cm}$ & $52.00 \mathrm{~cm}$ \\
\hline Group B & 18.05 inches & $201.88 \mathrm{lbs}$ & $51.38 \mathrm{~cm}$ & $50.88 \mathrm{~cm}$ \\
\hline
\end{tabular}

Table 3. Mean Post- Training Measurements

\begin{tabular}{|l|l|l|l|l|}
\hline & $\begin{array}{l}\text { Post vertical jump } \\
\text { height }\end{array}$ & Post 1RM squat & $\begin{array}{l}\text { Post R thigh } \\
\text { circumference }\end{array}$ & $\begin{array}{l}\text { Post L thigh } \\
\text { circumference }\end{array}$ \\
\hline Group A & 20.00 inches & $236.88 \mathrm{lbs}$ & $53.94 \mathrm{~cm}$ & $53.44 \mathrm{~cm}$ \\
\hline Group B & 20.00 inches & $226.88 \mathrm{lbs}$ & $52.63 \mathrm{~cm}$ & $52.38 \mathrm{~cm}$ \\
\hline
\end{tabular}

Table 4. Between Groups Analysis

\begin{tabular}{|l|l|l|l|}
\hline $\begin{array}{l}\text { Vertical jump height } \\
\text { between groups }\end{array}$ & $\begin{array}{l}\text { 1RM squat max between } \\
\text { groups }\end{array}$ & $\begin{array}{l}\text { R thigh circumference } \\
\text { between groups }\end{array}$ & $\begin{array}{l}\text { L thigh circumference } \\
\text { between groups }\end{array}$ \\
\hline$P=0.512$ & $P=0.120$ & $P=0.365$ & $P=0.937$ \\
\hline
\end{tabular}

\section{DISCUSSION}

The results of this study suggest with a small sample size that functional LL-BFR training ( $30 \% 1 \mathrm{RM})$ done twice weekly achieves similar results in power, strength, and hypertrophy as HLR training (70\% 1RM) done three times weekly within an 8-week period. These results further confirm the benefits of BFR training as mentioned in the meta-analysis done by Loenneke et al. ${ }^{4}$ The outcomes of this study give promise to the use of BFR bands in a clinical rehabilitation setting with patients that cannot tolerate high loads, especially during end-stage rehabilitation. This type of training may promote safety in the strength and conditioning communities by avoiding excessive loads while still achieving the same results. With that in mind, it is important to know that sRPE was found to be consistently higher in the BFR group throughout the life of the study, which is to be expected as reported by Loenneke et al and Clarkson et al. ${ }^{12,14}$ Although the loads are not as high, the perceived exertion is higher with the use of BFR bands, an important deciding factor when determining the use of BFR training with clients/patients.

Similarly, Wilson et al found that the indices of metabolic stress desired to induce a hypertrophic change could occur with lower technology cuffs, stating that pneumatic cuffs may not be feasible for many of the population. ${ }^{29}$ In their study, using knee wraps for open kinetic chain exercises resulted in greater metabolic stress to working muscles. ${ }^{8}$ It is theorized that this metabolic stress and subsequent accumulation increases the recruitment of higher threshold type II fibers. $8,15,16,17$ Previous research has supported the relationship between the activation of type II fibers and muscle protein synthesis required for hypertrophy and, eventually, strength. ${ }^{17}$

\section{Limitations}

There are several limitations to this study. Because of the subjects' class schedule, four subjects had inconsistent attendance during week 7, but were able to make up their sessions in week 8 . This altered the rest between days requirement at the end of training for the LLBFR group; however, it did not largely impact post-testing and results. In total, every participant completed their total number of workouts required.

The use of subjective rating for BFR bands may also be a limitation, as discomfort ratings of $7 / 10$ vary from subject to subject. However, this may have been acceptable were we to measure and verify venous occlusion as documented in the Wilson et al study. ${ }^{8}$ In further research, pressure cuffs that measure exact $\mathrm{mmHg}$ and retain their pressure in conjunction with verified arterial and venous occlusion may be used to provide more objective restriction. However, the use of simple bands allows for BFR training to be accessible to the general population at a nominal cost. 


\section{Conclusion}

The use of low intensity BFR training during functional exercises is a viable alternative to HLR training. We found that both the LLBFR and HLR groups had significant increases in power, strength, and thigh circumference. This was measured with the 1RM squat, vertical jump height, and thigh circumference. We found that there were no differences between the two groups in any category. In future studies, we would recommend a larger sample size and pneumatic cuffs that can hold pressure ratings in order to obtain objective measures.

\section{References}

1. Abe T, Yasuda T, Midorikawa T, et al. Skeletal muscle size and circulating IGF-1 are increased after two weeks of twice daily "KAATSU" resistance training. International Journal of KAATSU Training Research. 2005;1(1):6-12. doi:10.3806/ijktr.1.6.

2. Abe $T$, Kearns $C$, Sato $Y$. Muscle size and strength are increased following walk training with restricted venous blood flow from the leg muscle, Kaatsu-walk training. Journal of Applied Physiology. 2006;100(5):1460-1466. doi:10.1152/japplphysiol.01267.2005.

3. ACSM's Guidelines for Exercise Testing and Prescription. 9th ed. Philadelphia, PA: Wolters Kluwer/Lippincott Williams \& Wilkins Health; 2014.

4. Loenneke JP, Wilson GJ, Wilson JM. A Mechanistic Approach to Blood Flow Occlusion. International Journal of Sports Medicine. 2009;31(01):1-4. doi:10.1055/s-0029-1239499.

5. Brandner CR, Warmington SA, Kidgell DJ. Corticomotor Excitability is Increased Following an Acute Bout of Blood Flow Restriction Resistance Exercise. Frontiers in Human Neuroscience. 2015;9:1-10. doi:10.3389/fnhum.2015.00652.

6. Fujita S, Abe T, Drummond MJ, et al. Blood flow restriction during low-intensity resistance exercise increases S6K1 phosphorylation and muscle protein synthesis. Journal of Applied Physiology. 2007;103(1):903-910. doi:10.1152/japplphysiol.00195.2007.

7. Takarada $\mathrm{Y}$, Takazawa $\mathrm{H}$, Ishii N. Applications of vascular occlusion diminish disuse atrophy of knee extensor muscles. Medicine and Science in Sports and Exercise. 2000;32(12):2035-2039. doi:10.1097/00005768-20001200000011.

8. Wilson JM, Lowery RP, Joy JM, Loenneke JP, Naimo MA. Practical Blood Flow Restriction Training Increases Acute Determinants of Hypertrophy Without Increasing Indices of Muscle Damage. Journal of Strength and Conditioning Research. 2013;27(11):3068-3075. doi:10.1519/jsc.0b013e31828a1ffa.

9. Loenneke JP, Pujol TJ. The Use of Occlusion Training to Produce Muscle Hypertrophy. Strength and Conditioning Journal. 2009;31(3):77-84. doi:10.1519/ssc.0b013e3181a5a352.

10. Loenneke JP, Wilson JM, Marín PJ, Zourdos MC, Bemben MG. Low intensity blood flow restriction training: a metaanalysis. European Journal of Applied Physiology. 2011;112(5):1849-1859. doi:10.1007/s00421-011-2167-x.

11. Segal NA, Williams GN, Davis MC, Wallace RB, Mikesky AE. Efficacy of Blood Flow-Restricted, Low-Load Resistance Training in Women with Risk Factors for Symptomatic Knee Osteoarthritis. American Academy of Physical Medicine and Rehabilitation. 2015;7(4):376-384. doi:10.1016/j.pmrj.2014.09.014.

12. Clarkson MJ, Conway L, Warmington SA. Blood flow restriction walking and physical function in older adults: $A$ randomized control trial. Journal of Science and Medicine in Sport. 2017;20(12):1041-1046. doi:10.1016/j.jsams.2017.04.012.

13. Haff, GG and Triplett, NT. Essentials of Strength Training and Conditioning, $4^{\text {th }}$ Ed, Human Kinetics: Champaign, IL.

14. Loenneke JP, Allen KM, Mouser JG, et al. Blood flow restriction in the upper and lower limbs is predicted by limb circumference and systolic blood pressure. European Journal of Applied Physiology. 2015;115(2):397-405. doi:10.1007/s00421-014-3030-7.

15. Loenneke JP, Fahs $C$, Rossow L, Abe T, Bemben M. The anabolic benefits of venous blood flow restriction training may be induced by muscle cell swelling. Medical Hypotheses. 2012;78(1):151-154. doi:10.1016/j.mehy.2011.10.014.

16. Loenneke JP, Fahs CA, Rossow LM, et al. Effects of cuff width on arterial occlusion: implications for blood flow restricted exercise. European Journal of Applied Physiology. 2011;112(8):2903-2912. doi:10.1007/s00421-011-2266-8.

17. Loenneke JP, Fahs C, Wilson J, Bemben M. Blood flow restriction: The metabolite/volume threshold theory. Medical Hypotheses. 2011;77(5):748-752. doi:10.1016/j.mehy.2011.07.029. 